\title{
Neural Reactivity to Emotional Faces Mediates the Relationship Between Childhood Empathy and Adolescent Prosocial Behavior
}

\author{
John C. Flournoy ${ }^{1}$, Jennifer H. Pfeifer ${ }^{1}$, William E. Moore III $^{1}$, Allison Tackman ${ }^{1}$, Carrie L. \\ Masten $^{2}$, John C. Mazziotta ${ }^{2}$, Marco lacoboni ${ }^{2}$, and Mirella Dapretto ${ }^{2}$ \\ ${ }^{1}$ Department of Psychology, University of Oregon \\ ${ }^{2}$ Ahmanson-Lovelace Brain Mapping Center, University of California, Los Angeles
}

\begin{abstract}
Reactivity to others' emotions can result in empathic concern (EC), an important motivator of prosocial behavior, but can also result in personal distress (PD), which may hinder prosocial behavior. Examining neural substrates of emotional reactivity may elucidate how EC and PD differentially influence prosocial behavior. Participants $(\mathrm{N}=57)$ provided measures of $\mathrm{EC}, \mathrm{PD}$, prosocial behavior, and neural responses to emotional expressions at age 10 and 13. Initial EC predicted subsequent prosocial behavior. Initial EC and PD predicted subsequent reactivity to emotions in the inferior frontal gyrus (IFG) and inferior parietal lobule, respectively. Activity in the IFG, a region linked to mirror neuron processes, as well as cognitive control and language, mediated the relation between initial EC and subsequent prosocial behavior.
\end{abstract}

\section{Keywords}

empathy; mirror neuron system; prosocial behavior

Empathy is frequently defined as an affective response that is similar to what the other is feeling (Batson et al., 1987; Batson, 1998; Eisenberg, 2000). This shared experience of emotion, sometimes called affective resonance, can produce sympathy or feelings of empathic concern (Davis, 1983), widely considered to be important motivators of prosocial behavior (Eisenberg \& Miller, 1987; Eisenberg \& Fabes, 1998). Yet it can also result in personal distress, a predominantly self-focused negative reaction (Eisenberg \& Fabes, 1990). As children transition through adolescence, levels of empathic concern, personal distress, and prosocial behavior all change (Davis \& Franzoi, 1991; Eisenberg, Miller, Shell, McNalley, \& Shea, 1991; Eisenberg, Shell, Pasternack, Lennon, et al., 1987; Eisenberg, Cumberland, Guthrie, Murphy, \& Shepard, 2005; Hawk, Keijsers, Branje, Van der Graaff, Wied, \& Meeus, 2013), as do the neurobiological systems implicated in affective resonance (Pfeifer \& Blakemore, 2012). Such a convergence of changes makes it a critical period of development in which to examine these phenomena. The current study investigates whether and how empathic concern and personal distress interact to influence prosocial behavior during the transition to early adolescence, and uses neuroimaging to assess how affective

Corresponding Author: Jennifer H. Pfeifer, Department of Psychology, 1227 University of Oregon, Eugene, OR 97403-1227, jpfeifer@uoregon.edu, (541)346-1984 (work). 
resonance (in terms of neural reactivity to emotional faces) may explain some of this influence.

\section{Associations between Empathic Concern, Personal Distress, and Prosocial Behavior in the Transition to Early Adolescence}

In general, empathy and sympathy have been consistently positively associated with prosocial behavior throughout development (Barr \& Higgins-D'Alessandro, 2007; Brownell et al., 2013; Eisenberg, 2003; Eisenberg et al., 1991; Eisenberg et al., 1987; Farrant et al., 2012; Litvack-Miller et al., 1997). Associations between personal distress and prosocial behavior are somewhat less clear, but in general there is some evidence for a negative association, particularly when also accounting for trait levels of empathic concern or sympathy (Barr \& Higgins-D'Alessandro, 2007; Eisenberg et al., 1989; Eisenberg et al., 1991; Hulle et al., 2013; Trommsdorff, Friedlmeier, \& Mayer, 2007). Despite theoretical and empirical expectations of negative relations between the two (Batson, 1987; Eisenberg, Fabes, Miller, Fultz, Shell, Mathy, \& Reno, 1989), personal distress and empathic concern as measured by self-report (e.g., on the Interpersonal Reactivity Index; Davis, 1983) are often either positively correlated or unrelated in childhood and adolescence (Barr \& HigginsD'Alessandro, 2007; Davis \& Franzoi, 1991; Hawk et al., 2013; Litvack-Miller et al., 1997). Finally, cross-sectional and longitudinal data converge in reporting decreases in personal distress during adolescent development, compared with tendencies towards stability or increases in empathic concern (Hawk et al., 2013; Davis \& Franzoi, 1991; Eisenberg et al., 2005; Van der Graaff, Branje, Wied, Hawk, Lier, \& Meeus, 2014). Given the mixed literature, we therefore modeled both main effects and the interaction between empathic concern and personal distress.

\section{The Potential Role of Neural Reactivity to Emotional Expressions, as an index of Affective Resonance, in Empathic Concern and Personal Distress}

While there is research on neural correlates of prosocial behavior in adults (Greening et al., 2013; Masten, Morelli, \& Eisenberger, 2011; Morelli, Rameson, \& Lieberman, 2012; Utevsky \& Huettel, 2015) as well as during adolescence (Güroğlu, van den Bos, \& Crone, 2014; Telzer, Fuligni, Lieberman, \& Galván, 2013; Telzer, Masten, Berkman, Lieberman, \& Fuligni, 2010), and on neural mechanisms of empathic concern (or personal distress) during adolescence (Pfeifer, Iacoboni, Mazziotta, \& Dapretto, 2008; Decety, Michalska, \& Akitsuki, 2008; Marsh et al., 2013; Masten, Eisenberger, Pfeifer, Colich, \& Dapretto, 2013; Masten, Eisenberger, Pfeifer, \& Dapretto, 2010; Masten, Eisenberger, Pfeifer, \& Dapretto, 2013; Mella, Studer, Gilet, \& Labouvie-Vief, 2012), the authors are unaware of research investigating neural correlates of the link between empathy and prosocial behavior during the period of rapid change from childhood to adolescence. Although there are many processes and associated neural mechanisms implicated in such complex phenomena, examining neural responses to emotional expressions may provide insight into how even rudimentary and sometimes implicit processes may connect empathic concern and personal distress with different tendencies towards prosocial behavior. 
There are multiple candidate regions and systems that may be of interest when focusing on this basic level of neural reactivity to emotions. For example, as noted above, both empathic concern and personal distress may involve a shared experience of emotion, also called affective resonance; and concerned or distressed tendencies might also shape future proclivities to experience affective resonance. Affective resonance is proposed to be supported by the putative human mirror neuron system (MNS; Decety, 2010; Iacoboni, 2009), a network of brain regions that respond both to the execution and observation of goal directed actions including affective facial displays (emotional expressions). This network includes the bilateral inferior frontal gyrus (IFG), and rostral inferior parietal lobule (IPL) which receives higher order visual input from the posterior superior temporal sulcus (pSTS; Iacoboni \& Dapretto, 2006). While we use this network as a guide, it is important to note that these regions are involved in many processes, a point that will be expanded on in the discussion. In addition to these MNS regions, in both adults and children, empathy-related activity is seen in the amygdala and anterior insula, regions widely implicated in affective processing (Carr, Iacoboni, Dubeau, Mazziotta, \& Lenzi, 2003; Pfeifer et al., 2008). Together, these regions of interest (IFG, IPL, amygdala, and anterior insula) represent a logical starting point for investigating how a rudimentary construct like affective resonance indexed at the neural level may contribute to relationships between empathic concern, personal distress, and prosocial behavior.

In the current study, we expected that prosocial behavior would be associated with individual differences in empathic concern (EC), particularly by early adolescence. It is also possible that $\mathrm{EC}$ at an earlier age could predict future prosocial tendencies. For example, a child high in EC at age 10 may be motivated to maintain or increase her level of prosocial behavior over time, especially as more independent opportunities arise to do so. Furthermore, we expected that neural responses to emotional expressions in MNS regions (IFG, IPL) and/or in affective processing regions (amygdala, anterior insula) would account for some of (i.e., statistically mediate) the association between EC and prosocial behavior. Finally, as explained above, because personal distress (PD) may modify the effect of EC on prosocial behavior, we tested PD as a possible moderator of any relation between EC and prosocial behavior, as well as any mediation by neural responses to emotional expressions (see Figure 1 for diagrammatic representation of our theoretical model).

\section{Method}

Data analyzed are part of an existing longitudinal neuroimaging study. Typically-developing children, recruited from the broader Los Angeles metropolitan area, provided both fMRI and self-report data at two time points ( $\mathrm{N}=90$ and 57 at waves 1 and 2, respectively). Participants that did not return for the second wave (due to acquiring orthodontic work, moving out of the area, or lack of interest) and one participant that did not provide a response for our outcome of interest were excluded from the analysis, and thus all results arise from 56 participants ( 26 boys; mean age $=10.1$ and 13.1 years, $\mathrm{SD}=0.31$ and 0.31 , at waves 1 and 2 , respectively). Assent/consent was obtained from participants and their parents according to IRB guidelines. The sample was ethnically diverse, with $47 \%$ of parents identifying their child as white, $30 \%$ multiracial/multiethnic, $12 \%$ Hispanic or Latino/a, $4 \%$ black or AfricanAmerican, 2\% American Indian/Native American Hispanic or Latino/a, 2\% Asian or Pacific 
Islander, and $4 \%$ other. Household income ranged from less than $\$ 15 \mathrm{k}$, to more than $\$ 400 \mathrm{k}$ (median $=\$ 80-100 k$ ). Data were collected from June 2004 through February 2009.

\section{Self Report Measures}

Empathy-Participants filled out the Interpersonal Reactivity Index (IRI; Davis, 1983; Litvak-Miller, 1997), which provided measures of empathic concern (EC) and personal distress (PD), and has been previously used with this age group (Eisenberg et al., 1991; Eisenberg et al., 1987). Scores were linearly transformed from the original scale to a percent of the maximum score possible (Cohen, Cohen, Aiken, \& West, 1999) to aid in interpretation. Means, standard deviations, and reliability coefficients are reported in Table 1. Note that although EC has a small alpha coefficient at Wave 1, significant correlations with several closely related measures provide evidence of convergent validity (Supplementary Table S3).

Prosocial Behavior-Participants also completed measures from the 4-H Study of Positive Youth Development survey (PYD; Lerner et al., 2005), which provides two items relevant to prosocial behavior (as opposed to prosocial values). The first item assesses the number of hours per week children spend volunteering: "During an average week, how many hours do you spend helping other people without getting paid (such as helping out at a hospital, daycare center, food shelf, youth program, community service agency, or doing other things) to make your city a better place for people to live?" Response options were " 0 , 1, 2, 3-5, 6-10, 11 or more." These responses were recoded to reflect the number of hours reported, or the average of the range given (e.g., 4 for the "3-5" response). The high end was coded as 11 hours. The second item asked participants if they are often kind to other children, with responses ranging from 1 to 4 . The prosocial behavior outcome was formed by first log-transforming the volunteering item, transforming both items to a percent of their respective maximum possible scores, and then taking the mean of both items (Wave $1 \mathrm{M}=$ 49.1, $\mathrm{SD}=16.2$; Wave $2 \mathrm{M}=48.0, \mathrm{SD}=18.2$ ). The 2-item index provides better conceptual coverage of the prosocial behavior construct than either item by itself. Although the kindness and volunteerism items were not significantly correlated at Wave $1(r=-.11)$ or Wave $2(r=.14)$, the aggregate score was significantly correlated with many self-report measures of prosocial attitudes and values (e.g., helping, equality and justice, and social responsibility; see Supplementary Table S3) at both waves, providing evidence for its convergent validity.

All measures except for the IRI were part of the PYD, which is a collection of measurements related to the "Cs of PYD" (competence, confidence, connection, character, caring, and compassion; Lerner et al., 2005). Also included in the PYD are measures of activities, individual and ecological assets, developmental regulation, pubertal status, problem behaviors, and demographics (not all of which are pertinent to this analysis). References for relevant measures within the PYD may be found in Supplementary Table S2.

\section{fMRI Paradigm}

During fMRI, participants were instructed to "look at the expression on each face" while passively observing facial expressions of emotion (angry, fearful, sad, happy, and neutral) 
from the NimStim set (Tottenham et al., 2009). Each face was displayed for 2 seconds with an inter-trial interval that varied between $0.5-1.5 \mathrm{~s}(\mathrm{M}=1 \mathrm{~s})$. The order of emotion presentation was counterbalanced to optimize the detection of contrast between emotions (Wager \& Nichols, 2003). A total of 96 whole-brain volumes were collected comprising 80 emotional face events (16 per emotion) and 16 null (fixation cross) events.

This paradigm was utilized because of its ability to elicit neural reactivity to emotional expressions in the regions of interest supporting affective resonance listed in the introduction (IFG, IPL, amygdala, anterior insula). Observation of emotional expressions minimizes contamination of neural activity by motion inherent during execution of actions, and can be mapped directly onto the experience of sharing someone else's emotions, which is frequently implicated in both empathic concern and personal distress (Davis, 1983). In other words, when encountering someone else looking sad (for example), an individual predisposed toward more or less empathic concern and/or personal distress may show stronger or weaker responses in these regions of interest. This might inform our understanding of prosocial behavior because an automatic neural response that favors a certain type of empathic engagement with emotional stimuli may provide a strong foundation for motivating effortful prosocial behavior in part because that engagement is not effortful. This task is not meant to directly evoke sympathy or empathic concern itself (unlike e.g., Bernhardt, Klimecki, Leiberg, \& Singer, 2013; Decety, Chen, Harenski, \& Kiehl, 2013; see Bernhardt \& Singer, 2012 and Decety, 2011 for overviews), emotion regulation (e.g., McRae, Misra, Prasad, Pereira, \& Gross, 2012; Zaki, Ochsner, Hanelin, Wager, \& Mackey, 2007), or any number of more proximal constructs, and is thus arguably more conservative. Prior publications of subsets of participants from this dataset reveal that at the group level, observation of emotional expressions indeed engages these regions (see Pfeifer et al., 2008; Pfeifer et al., 2011). Finally, a large-scale, automated meta-analysis of studies of the neural response to emotional faces also indicates that this task would be expected to elicit activity in the systems we wish to investigate (see Supplementary Figure S2).

\section{fMRI Acquisition and Analysis}

fMRI data were acquired using a Siemens Allegra 3.0T scanner. Functional images were collected in a $4 \mathrm{~m}, 54 \mathrm{~s}$ session of blood oxygen level dependent echo-planar imaging (BOLD-EPI; TR $=3000 \mathrm{~ms}, \mathrm{TE}=25 \mathrm{~ms}$, flip angle $=90$, matrix size 64 by $64, \mathrm{FOV}=20 \mathrm{~cm}$, 36 slices, $3.125 \mathrm{~mm}$ in-plane resolution, $3 \mathrm{~mm}$ thick). Co-planar high-resolution structural images were also obtained for each participant (T2-weighted echo-planar imaging volume, spin-echo, $\mathrm{TR}=5000 \mathrm{~ms}, \mathrm{TE}=33 \mathrm{~ms}$, matrix size 128 by $128, \mathrm{FOV}=20 \mathrm{~cm}, 36$ slices, $1.56 \mathrm{~mm}$ in-plane resolution, $3 \mathrm{~mm}$ thick). Stimuli were presented to participants through high-resolution magnet-compatible goggles (Resonance Technology, Inc.).

DICOM images were converted to NIfTI format using MRIConvert (http://lcni.uoregon.edu/ jolinda/MRIConvert/), and all non-brain voxels were removed using FSL's Brain Extraction Tool (Smith, 2002). Preprocessing, first, and second level models were conducted in SPM12b (Wellcome Department of Cognitive Neurology, London, UK; http:// www.fil.ion.ucl.ac.uk/spm/). Functional images were realigned to the mean image of each run, coregistered to the anatomical image, and warped to MNI space using the EPI template 
included with SPM12b. Finally, functional images were smoothed using a $9 \mathrm{~mm}$ full-width at half maximum Gaussian kernel.

Neural responses to each emotion were modeled with a fixed effects GLM using the canonical hemodynamic response function with time and dispersion derivatives, $128 \mathrm{~s}$ high pass filter, correction for serial autocorrelation (AR1), and optimally thresholded explicit mask (Ridgway et al., 2009). Position parameters from the realignment step above were entered as regressors of no interest to ameliorate the influence of motion. Only one participant had a transverse displacement $>3 \mathrm{~mm}$, and only one subject had a rotation > 3deg. Only two participants had $>10 \%$ of volumes displaced more than $1 \mathrm{~mm}$, and one participant had $>8 \%$ of volumes displaced more than $1 \mathrm{~mm}$. Running the analyses without these three subjects does not change the significance of any results. Estimates of amplitude, width, time to peak, and area under the curve were recalculated from the fitted responses of each trial type (emotion) in order to create summary statistic images that more robustly describe the hemodynamic response (Lindquist \& Wager, 2007; http:// wagerlab.colorado.edu/tools). Random effects models at the group level included the contrasts for all emotional expressions versus rest regressed on empathic concern, personal distress, and their interaction as described below.

\section{Analytic Plan}

The relation between empathic concern, prosocial behavior, and neural response to emotional expressions was examined within and across waves (fMRI and questionnaires were collected at both waves). Neural activity significantly associated with empathic concern was then tested as a mediator of any relation between empathic concern and prosocial behavior.

Based on the literature reviewed above, we tested whether empathic concern (EC) accounted for variance in prosocial behavior within each wave, as well as whether EC at wave 1 accounted for variance in prosocial behavior at wave 2. We included personal distress (PD) and the interaction of empathic concern and personal distress (ECxPD) to account for possible moderation. For the cross-wave autoregressive model (Twisk, 2003; Zapf, Dormann, \& Frese, 1996), prosocial behavior at wave 1 was entered as a predictor of prosocial behavior at wave 2 .

We then tested whether neural responses to emotional expressions explained some or part of the relation between prosocial behavior and empathic concern or personal distress. As in prior studies (Pfeifer et al., 2008; Pfeifer et al., 2011; Moore et al., 2012), emotion reactivity was indexed by averaging across responses to all expressions (angry, fearful, sad, happy, and neutral), relative to fixation. "Neutral" expressions were included in the average because they are not an effective control, as they elicit significant activity in affective processing regions like the amygdala (Van der Gaag, Mindera, \& Keysers, 2007) and are often perceived as mildly negative (Lee, Kang, Park, Kim, \& An, 2008; Kesler-West et al., 2001; Russel \& Fehr, 1987). First, EC, PD, and EC $\times$ PD were entered in whole brain regressions within each wave, as well as across waves (i.e., self-report data from wave 1 predicting neural data from wave 2). Thresholds for reporting neural activity were determined using 3dClustSim, part of AFNI (Cox \& Hyde, 1997), which estimates combinations of voxel- 
wise $p$-values and cluster extents (in voxels) that together control the false discovery rate (set at $p<.05$ in this case). We also investigated activity within a mask of a priori brain regions, all defined by the Harvard Oxford Cortical and Subcortical Structural Atlases bundled with FSL (Desikan et al., 2006; Goldstein et al., 2007), comprising the inferior frontal gyrus (pars opercularis and pars triangularis), rostral inferior parietal lobule (anterior and posterior divisions of supramarginal gyrus), anterior insula, and amygdala. Summaries of activity (specifically, the first eigenvariate) in significant clusters were extracted from each participant using the REX toolbox (Whitfield-Gabrieli, 2009), and were used in tests of mediation.

Statistical tests of mediation were conducted using the mediation package in R (Tingley, Yamamoto, Hirose, Keele, \& Imai, 2013), which corrects some problems with the typical path-tracing approach to estimating the mediated effect, and which allows mediation to be tested in a wide variety of model types (Imai, Keele, Tingley, \& Yamamoto, 2011). Unlike the more common methods popularized by Baron and Kenny (1986) and Preacher and Hayes (2004), this method does not estimate mediated effects by multiplying estimated coefficients, and instead relies on counterfactual reasoning that extends Rubin's causal model (1974). The algorithm estimates the average direct effect (ADE) from the predictor variable (in this case, EC), to the outcome (prosocial behavior), as well as the average causal mediation effect (ACME) from predictor to outcome via the mediator (neural activity). Covariates can be included and moderation of both the ADE and ACME can be tested. We tested whether neural activity associated with EC mediated any effect of EC on prosocial behavior. We included PD as a moderating variable, and any brain activity associated with $\mathrm{PD}$ or $\mathrm{EC} \times \mathrm{PD}$ as covariates. When testing mediation of effects across waves, prosocial behavior at wave 1 was also included as a covariate to account for stability of prosocial behavior over time.

\section{Results}

\section{Associations between Empathic Concern, Personal Distress, and Prosocial Behavior}

Within wave 1, empathic concern (EC) did not account for a significant amount of variance in prosocial behavior. Within wave 2, EC was significantly associated with prosocial behavior $(b=0.66, \mathrm{SE}=0.17, p<.001)$. In the cross-lagged model, wave $1 \mathrm{EC}$ significantly positively predicted prosocial behavior at wave 2 , controlling for prosocial behavior at wave 1 (Table 2). Including socioeconomic status in the above analyses did not substantively change the results. The estimate of the temporally reversed association between prosocial behavior at wave 1 and EC at wave 2 was positive, but not significantly different from zero $(b=0.18, S E=0.10, p=.07)$. Finally, while parental levels of helping significantly predict children's prosocial behavior both in the within-wave model at wave $2(b=7.29, \mathrm{SE}=2.32$, $p<.01)$, and the cross-lagged model $(b=7.66, \mathrm{SE}=2.55, p<.01)$, controlling for this variable does not substantively change the above results. Correlations among all variables of interest can be found in Supplementary Table S1. 


\section{Associations between Empathic Concern, Personal Distress, and Neural Response to Emotional Expressions}

To confirm that our stimuli elicited the expected neural response, a $t$-test statistic map for the estimate of average per-voxel activity was analyzed using the Neurosynth Image Decoder (Yarkoni et al, 2011), which yielded high correlations with statistical maps associated with expected meta-analytic features (e.g., the highest correlation was with the 'faces' feature, $r=$. 452; see Supplementary Table S9 for more information).

Regressing neural activity at wave 2 on EC, PD and their interaction at wave 1 revealed four significant clusters. For this analysis, the voxel-wise threshold was $p<.005$ with cluster extent $\mathrm{k}>41$ for the search within our a priori mask; and voxel-wise $p<.005$ with cluster extent $\mathrm{k}>74$ voxels for the whole brain search (Table 3). First, in the a priori region of interest search, greater EC at age 10 was associated with more activity in the inferior frontal gyrus (IFG) in response to emotional expressions at age 13, while greater PD at age 10 was associated with less activity in the inferior parietal lobule (IPL) at age 13 (Figure 2). In the whole-brain search, the interaction between PD and EC at age 10 was also associated with less activity in the perigenual anterior cingulate cortex (pACC) and cuneus at age 13 (Figure 2). All associations were estimated to be in the same direction across emotions, with some variation in the significance of those estimates (see Supplementary Figures S5 and S6). Correlations among significant clusters can be found in Supplementary Table S4. Within wave 1, no significant brain-behavior correlations were detected. Results for whole brain and a priori region of interest regressions within wave 2 can be found in Supplementary Table S13 and Figure S8.

\section{Mediation of Behavioral Associations by Neural Response to Emotional Expressions}

EC at age 10 predicted prosocial behavior at age 13, as well as neural activity in the left IFG at age 13, and so we tested whether activity in the left IFG mediates the relationship between EC and prosocial behavior (see Figure 1 for an illustrative diagram of this model). As described in the analytic plan, we included wave 1 prosocial behavior, PD and its interaction with EC, and summaries of activity in clusters detected in the whole-brain regression: IPL, pACC, and cuneus at wave 2. There was a positive, significant effect of EC on prosocial behavior mediated by IFG, a non-significant positive direct effect, and a significant positive total effect (Table 4). In short, the significant total effect of EC on prosocial behavior is accounted for largely by activity in IFG in response to emotional stimuli. This mediated effect was not moderated by PD, as evidenced by no significant difference ( $p=.49$ ) between the estimated average causal mediation effect (ACME) in models conditional on high levels of PD (mean $+1 \mathrm{SD}$ ) versus low levels of PD (mean - 1 SD). Mediation was robust to the exclusion of all covariates, including PD and ECxPD, except for neural activity in the IPL (see Supplementary Table S4b for correlations of prosocial behavior at wave 1 and 2 with all significant clusters).

\section{Discussion}

We find that empathy at age 10 prospectively predicts prosocial behavior at age 13 and that this association is partly mediated by neural response to emotional expressions in the left 
IFG at age 13. The association of empathic concern and personal distress with activity in regions often identified as part of the human MNS, including the left IFG, is consistent with the notion that this system supports a shared experience of emotion (Pfeifer et al., 2008). This longitudinal relationship suggests that reactivity to emotions in this system may be shaped by prior levels of empathic concern, which then supports translation of trait-level concern into prosocial action. Our finding that empathic concern is related to concurrent prosocial behavior at age 13 is consistent with prior research (Eisenberg et al., 1987; Eisenberg et al., 1991).

Activity in the IFG has been strongly linked to action imitation and mental simulation, though it has also been linked to linguistic processing, as well as cognitive control. With regard to MNS-like processes, the IFG may decode the goals of an observed action (Grèzes \& Decety, 2001; Iacoboni \& Dapretto, 2006; Molenberghs, Cunnington, \& Mattingley, 2012), especially when there is a conflict between the perspective of the self and the other (van der Meer, Groenewold, Nolen, Pijnenborg, \& Aleman, 2011). The left IFG has also been long associated with verbal fluency (Broca, 1861), and modern neuroimaging supports this link (Costafreda et al., 2006). Activity in this region linked to empathy may therefore reflect semantic and conceptual engagement with emotional content. Many studies have also found that the left IFG is important for cognitive control (Bahlmann et al., 2012; Dwyer et al., 2014; Herwig et al., 2007), which in the context of prosocial behavior may be important to aid planning and execution of effortful action. A quantitative meta-analysis found four distinct clusters of peak activity reported within IFG, which corresponded to semantic processing, working memory, motor control, and empathy tasks (Liakakis et al., 2011). Interestingly, the IFG peak reported in this paper is closest to the working memory and semantic processing regions, suggesting that linguistic engagement with emotional stimuli, or perhaps general levels of executive function, may help link concern with prosocial action. Future work could examine tasks that manipulate behavior in these four domains within the same participants to better characterize the nature of the contribution by the left IFG.

The IPL is also part of the MNS (Iacoboni \& Dapretto, 2006; Molenberghs et al., 2012), and thus the negative association with previous levels of personal distress suggests that tendencies to experience distress in the presence of emotion may lead to lower levels of engaging affective resonance processes. Buhle and colleagues (2013) note that this region is also implicated in processing observed actions, decoding intentions, and processing semantic information (Rapp, Mutschler, \& Erb, 2012; Van Overwalle \& Baetens, 2009; Vigneau et al., 2006), and that all of these processes may be utilized during emotional reappraisal. In short, lower levels of neural activity related to processing negative emotional stimuli, and perhaps action processing or inhibition, are predicted by earlier levels of personal distress, possibly as a result of developmental downregulation.

Mediation of the link between empathic concern and prosocial behavior by neural reactivity in the left IFG suggests that empathic concern leads to future prosocial behavior in part through shaping engagement of this region in response to emotional stimuli. Heightened processing in this region implicated in simulation, shared experiencing, language, and cognitive control may lead to greater salience of the need of a conspecific, or a more nuanced and personal understanding of that need, and thus lead to increased motivation to 
act prosocially. This is consistent with the literature showing that automatic mimicry is a learned, unconscious process, and that it may increase prosocial behavior (Baaren, Holland, Kawakami, \& Knippenberg, 2004; Heyes, 2011). As noted above, linguistic and/or cognitive control processes are also likely explanations of activity we find associated with EC, and offer a complementary explanation for the mediated effects. For example, linguistic processing of affect has been shown to attenuate negative emotion behaviorally and neurally (Brownell et al., 2013; Lieberman et al., 2007; Warner et al., 2006; Wilson \& Schooler, 1991). Perhaps children higher in EC at an earlier age learn to engage more symbolically with emotional experience, which facilitates committed prosocial behavior. Thus, empathic concern may motivate engagement in prosocial behavior in part by encouraging the automatic processing of socioemotional content by psychological processes supported by the left IFG.

\section{Limitations and Future Directions}

The observed brain activity during passive viewing of emotional expressions likely represents participants' default patterns of functioning during engagement with emotional expressions, rather than any kind of intentional processing of these stimuli (or overt empathy). As such, we interpret the longitudinal associations with empathic concern and personal distress, and the mediation of the longitudinal association between empathic concern and prosocial behavior, as reflecting individual differences in tendencies to engage certain neural systems when confronted with facial expressions, and socioemotional stimuli more broadly.

However, these specific neural systems could be explored more thoroughly using neuroimaging paradigms that can evaluate theoretically driven process models and/or isolate specific processes (e.g., a task requiring linguistic engagement with emotive stimuli, or a prosocial decision making task). In addition, while our results are suggestive, to begin to establish causality future work should attempt to directly manipulate the independent variable (empathic concern) as well as the mediator (affective resonance) when feasible (see Bullock, Green, \& Ha, 2010 for an in depth discussion of this and other challenges for causal mediation analyses).

It is also important to note that many cognitive processes other than those discussed in this article are presumably involved in both sustained long-term prosocial behavior and more momentary types. For example, there is evidence that perspective-taking, which continues to develop until late adolescence, mediates age related differences in sharing (Güroğlu, van den Bos, \& Crone, 2014). There are also developmental changes in the degree to which the relational identity of one's interaction partner predicts sharing behavior, another important factor to consider in exploring motivations of helping behavior as well, especially given peer influences on prosocial behavior during adolescence (van Goethem, van Hoof, van Aken, Orobio de Castro, \& Raaijmakers, 2014; van Hoorn, van Dijk, Meuwese, Rieffe, \& Crone, 2014). 


\section{Concluding Comments}

In conclusion, these results describe a possible set of associations that developmentally links empathic concern to prosocial behavior via a brain region implicated in affective mirroring processes, language, and cognitive control. The automatic neural responses to socioemotional stimuli that gave rise to activity in this region may not be accessible to selfreport or behavioral measures, highlighting the value of this approach. Future work may build on these results to characterize the way empathic concern shapes these automatic processes over this developmental period.

\section{Supplementary Material}

Refer to Web version on PubMed Central for supplementary material.

\section{Acknowledgments}

For generous support the authors wish to thank the Santa Fe Institute Consortium, Brain Mapping Medical Research Organization, Brain Mapping Support Foundation, Pierson-Lovelace Foundation, The Ahmanson Foundation, William M. and Linda R. Dietel Philanthropic Fund at the Northern Piedmont Community Foundation, Tamkin Foundation, Jennifer Jones-Simon Foundation, Capital Group Companies Charitable Foundation, Robson Family and Northstar Fund. The project described was supported by Grant Numbers RR12169, RR13642 and RR00865 from the National Center for Research Resources (NCRR), a component of the National Institutes of Health (NIH); its contents are solely the responsibility of the authors and do not necessarily represent the official views of NCR or NIH.

\section{References}

Bahlmann J, Korb FM, Gratton C, Friederici AD. Levels of Integration in Cognitive Control and Sequence Processing in the Prefrontal Cortex. PLoS ONE. 2012; 7(8):e43774. [PubMed: 22952762]

Baron RM, Kenny DA. The moderator-mediator variable distinction in social psychological research: Conceptual, strategic, and statistical considerations. Journal of Personality and Social Psychology. 1986; 51(6):1173-1182. [PubMed: 3806354]

Barr JJ, Higgins-D'Alessandro A. Adolescent Empathy and Prosocial Behavior in the Multidimensional Context of School Culture. Journal of Genetic Psychology. 2007; 168(3):231250. [PubMed: 18200888]

Batson, CD. Prosocial motivation: Is it ever truly altruistic?. In: Berkowitz, L., editor. Advances in experimental social psychology. Vol. 20. New York: Academic Press; 1987. p. 65-122.

Bernhardt BC, Klimecki OM, Leiberg S, Singer T. Structural Covariance Networks of the Dorsal Anterior Insula Predict Females' Individual Differences in Empathic Responding. Cerebral Cortex. 2013 bht072.

Bernhardt BC, Singer T. The Neural Basis of Empathy. Annual Review of Neuroscience. 2012; 35(1): 1-23.

Broca P. Remarques sur le siège de la faculté du langage articulé, suivies d'une observation d'aphémie (perte de la parole). Bulletins de La Société D'anatomie. 1861; 36:330-57.

Brownell CA, Svetlova M, Anderson R, Nichols SR, Drummond J. Socialization of Early Prosocial Behavior: Parents' Talk About Emotions is Associated With Sharing and Helping in Toddlers. Infancy. 2013; 18(1):91-119. [PubMed: 23264753]

Buhle JT, Silvers JA, Wager TD, Lopez R, Onyemekwu C, Kober H, et al. Ochsner KN. Cognitive Reappraisal of Emotion: A Meta-Analysis of Human Neuroimaging Studies. Cerebral Cortex. 2013 bht154.

Bullock JG, Green DP, Ha SE. Yes, but what's the mechanism? (don't expect an easy answer). Journal of Personality and Social Psychology. 2010; 98(4):550-558. [PubMed: 20307128] 
Carr L, Iacoboni M, Dubeau MC, Mazziotta JC, Lenzi GL. Neural mechanisms of empathy in humans: A relay from neural systems for imitation to limbic areas. Proceedings of the National Academy of Sciences. 2003; 100(9):5497-5502.

Cohen P, Cohen J, Aiken LS, West SG. The Problem of Units and the Circumstance for POMP. Multivariate Behavioral Research. 1999; 34(3):315-346.

Costafreda SG, Fu CHY, Lee L, Everitt B, Brammer MJ, David AS. A systematic review and quantitative appraisal of fMRI studies of verbal fluency: Role of the left inferior frontal gyrus. Human Brain Mapping. 2006; 27(10):799-810. [PubMed: 16511886]

Cox RW, Hyde JS. Software tools for analysis and visualization of fMRI data. NMR in Biomedicine. 1997; 10(4-5):171-178. [PubMed: 9430344]

Davis MH. Measuring individual differences in empathy: Evidence for a multidimensional approach. Journal of Personality and Social Psychology. 1983; 44(1):113-126.

Davis MH, Franzoi SL. Stability and change in adolescent self-consciousness and empathy. Journal of Research in Personality. 1991; 25(1):70-87.

Decety J. The neurodevelopment of empathy in humans. Developmental Neuroscience. 2010; 32(4): 257-267. [PubMed: 20805682]

Decety J. Dissecting the Neural Mechanisms Mediating Empathy. Emotion Review. 2011; 3(1):92108.

Decety J, Chen C, Harenski C, Kiehl KA. An fMRI study of affective perspective taking in individuals with psychopathy: imagining another in pain does not evoke empathy. Frontiers in Human Neuroscience. 2013; 7

Decety J, Grèzes J. The power of simulation: Imagining one's own and other's behavior. Brain Research. 2006; 1079(1):4-14. [PubMed: 16460715]

Desikan RS, Ségonne F, Fischl B, Quinn BT, Dickerson BC, Blacker D, et al. Killiany RJ. An automated labeling system for subdividing the human cerebral cortex on MRI scans into gyral based regions of interest. NeuroImage. 2006; 31(3):968-980. [PubMed: 16530430]

Dwyer DB, Harrison BJ, Yücel M, Whittle S, Zalesky A, Pantelis C, et al. Fornito A. Large-scale brain network dynamics supporting adolescent cognitive control. The Journal of Neuroscience: The Official Journal of the Society for Neuroscience. 2014; 34(42):14096-14107. [PubMed: 25319705]

Eisenberg, N. Prosocial motives, emotions, and behavior: The better angels of our nature. Washington, DC, US: American Psychological Association; 2010. Empathy-related responding: Links with self-regulation, moral judgment, and moral behavior; p. 129-148.

Eisenberg, N. Prosocial behavior, empathy, and sympathy. In: Bornstein, MH.Davidson, L.Keyes, CLM., Moore, KA., editors. Well-being: Positive development across the life course. Mahwah, NJ, US: Lawrence Erlbaum Associates Publishers; 2003. p. 253-265.

Eisenberg N, Cumberland A, Guthrie IK, Murphy BC, Shepard SA. Age changes in prosocial responding and moral reasoning in adolescence and early adulthood. Journal of Research on Adolescence. 2005; 15(3):235-260. [PubMed: 20592955]

Eisenberg N, Fabes RA, Miller PA, Fultz J, Shell R, Mathy RM, Reno RR. Relation of sympathy and personal distress to prosocial behavior: a multimethod study. Journal of Personality and Social Psychology. 1989; 57(1):55. [PubMed: 2754604]

Eisenberg N, Miller PA. The relation of empathy to prosocial and related behaviors. Psychological Bulletin. 1987; 101(1):91-119. [PubMed: 3562705]

Eisenberg N, Miller PA, Shell R, McNalley S, Shea C. Prosocial development in adolescence: A longitudinal study. Developmental Psychology. 1991; 27(5):849-857.

Eisenberg N, Shell R, Pasternack J, Lennon R, et al. Prosocial development in middle childhood: A longitudinal study. Developmental Psychology. 1987; 23(5):712-718.

Farrant BM, Devine TAJ, Maybery MT, Fletcher J. Empathy, Perspective Taking and Prosocial Behaviour: The Importance of Parenting Practices. Infant and Child Development. 2012; 21(2): 175-188.

Gerardin E, Sirigu A, Lehéricy S, Poline JB, Gaymard B, Marsault C, et al. Bihan DL. Partially Overlapping Neural Networks for Real and Imagined Hand Movements. Cerebral Cortex. 2000; 10(11):1093-1104. [PubMed: 11053230] 
Goldstein JM, Seidman LJ, Makris N, Ahern T, O'Brien LM, Caviness VS Jr, et al. Tsuang MT. Hypothalamic Abnormalities in Schizophrenia: Sex Effects and Genetic Vulnerability. Biological Psychiatry. 2007; 61(8):935-945. [PubMed: 17046727]

Greening S, Norton L, Virani K, Ty A, Mitchell D, Finger E. Individual differences in the anterior insula are associated with the likelihood of financially helping versus harming others. Cognitive, Affective, \& Behavioral Neuroscience. 2013; 14(1):266-277.

Grèzes J, Decety J. Functional anatomy of execution, mental simulation, observation, and verb generation of actions: A meta-analysis. Human Brain Mapping. 2001; 12(1):1-19. [PubMed: 11198101]

Güroğlu B, van den Bos W, Crone EA. Sharing and giving across adolescence: an experimental study examining the development of prosocial behavior. Frontiers in Psychology. 2014; 5

Hawk ST, Keijsers L, Branje SJ, Graaff JVD, Wied MD, Meeus W. Examining the interpersonal reactivity index (IRI) among early and late adolescents and their mothers. Journal of Personality Assessment. 2013; 95(1):96-106. [PubMed: 22731809]

Herwig U, Baumgartner T, Kaffenberger T, Brühl A, Kottlow M, Schreiter-Gasser U, et al. Rufer M. Modulation of anticipatory emotion and perception processing by cognitive control. NeuroImage. 2007; 37(2):652-662. [PubMed: 17588776]

Hulle CV, Zahn-Waxler C, Robinson JL, Rhee SH, Hastings PD, Knafo A. Autonomic correlates of children's concern and disregard for others. Social Neuroscience. 2013; 8(4):275-290. [PubMed: 23802120]

Iacoboni M. Imitation, empathy, and mirror neurons. Annual Review of Psychology. 2009; 60:653670.

Iacoboni M, Dapretto M. The mirror neuron system and the consequences of its dysfunction. Nature Reviews Neuroscience. 2006; 7(12):942-951. [PubMed: 17115076]

Imai K, Keele L, Tingley D, Yamamoto T. Unpacking the Black Box of Causality: Learning about Causal Mechanisms from Experimental and Observational Studies. American Political Science Review. 2011; 105(04):765-789.

Kesler-West ML, Andersen AH, Smith CD, Avison MJ, Davis CE, Kryscio RJ, Blonder LX. Neural substrates of facial emotion processing using fMRI. Brain Research. Cognitive Brain Research. 2001; 11(2):213-226. [PubMed: 11275483]

Lee E, Kang JI, Park IH, Kim JJ, An SK. Is a neutral face really evaluated as being emotionally neutral? Psychiatry Research. 2008; 157(1-3):77-85. [PubMed: 17804083]

Lerner RM, Lerner JV, Almerigi JB, Theokas C, Phelps E, Gestsdottir S, et al. Eye Avon. Positive Youth Development, Participation in Community Youth Development Programs, and Community Contributions of Fifth-Grade Adolescents Findings From the First Wave Of the 4-H Study of Positive Youth Development. The Journal of Early Adolescence. 2005; 25(1):17-71.

Liakakis G, Nickel J, Seitz RJ. Diversity of the inferior frontal gyrus-A meta-analysis of neuroimaging studies. Behavioural Brain Research. 2011; 225(1):341-347. [PubMed: 21729721]

Lindquist MA, Wager TD. Validity and power in hemodynamic response modeling: A comparison study and a new approach. Human Brain Mapping. 2007; 28(8):764-784. [PubMed: 17094118]

Litvack-Miller W, McDougall D, Romney DM. The structure of empathy during middle childhood and its relationship to prosocial behavior. Genetic, Social, and General Psychology Monographs. 1997; 123(3):303-324.

Masten CL, Morelli SA, Eisenberger NI. An fMRI investigation of empathy for "social pain" and subsequent prosocial behavior. NeuroImage. 2011; 55(1):381-388. [PubMed: 21122817]

Molenberghs P, Cunnington R, Mattingley JB. Brain regions with mirror properties: A meta-analysis of 125 human fMRI studies. Neuroscience \& Biobehavioral Reviews. 2012; 36(1):341-349. [PubMed: 21782846]

Moore WE, Pfeifer JH, Masten CL, Mazziotta JC, Iacoboni M, Dapretto M. Facing puberty: associations between pubertal development and neural responses to affective facial displays. Social Cognitive and Affective Neuroscience. 2012; 7(1):35-43. [PubMed: 22228752]

Morelli SA, Rameson LT, Lieberman MD. The neural components of empathy: Predicting daily prosocial behavior. Social Cognitive and Affective Neuroscience. 2012 nss088. 
Pfeifer JH, Blakemore SJ. Adolescent social cognitive and affective neuroscience: past, present, and future. Social Cognitive and Affective Neuroscience. 2012; 7(1):1-10. [PubMed: 22228750]

Pfeifer JH, Iacoboni M, Mazziotta JC, Dapretto M. Mirroring others' emotions relates to empathy and interpersonal competence in children. NeuroImage. 2008; 39(4):2076-2085. [PubMed: 18082427]

Pfeifer JH, Kahn LE, Merchant JS, Peake SJ, Veroude K, Masten CL, et al. Dapretto M. Longitudinal Change in the Neural Bases of Adolescent Social Self-Evaluations: Effects of Age and Pubertal Development. The Journal of Neuroscience. 2013; 33(17):7415-7419. [PubMed: 23616547]

Pfeifer JH, Masten CL, Moore WE III, Oswald TM, Mazziotta JC, Iacoboni M, Dapretto M. Entering Adolescence: Resistance to Peer Influence, Risky Behavior, and Neural Changes in Emotion Reactivity. Neuron. 2011; 69(5):1029-1036. [PubMed: 21382560]

Preacher KJ, Hayes AF. SPSS and SAS procedures for estimating indirect effects in simple mediation models. Behavior Research Methods, Instruments, \& Computers. 2004; 36(4):717-731.

R Core Team. R: A Language and Environment for Statistical Computing. Vienna, Austria: R Foundation for Statistical Computing; 2014. Retrieved from http://www.R-project.org

Rapp AM, Mutschler DE, Erb M. Where in the brain is nonliteral language? A coordinate-based metaanalysis of functional magnetic resonance imaging studies. NeuroImage. 2012; 63(1):600-610. [PubMed: 22759997]

Ridgway GR, Omar R, Ourselin S, Hill DLG, Warren JD, Fox NC. Issues with threshold masking in voxel-based morphometry of atrophied brains. NeuroImage. 2009; 44(1):99-111. [PubMed: 18848632]

Rubin DB. Estimating causal effects of treatments in randomized and nonrandomized studies. Journal of Educational Psychology. 1974; 66(5):688-701.

Russell JA, Fehr B. Relativity in the perception of emotion in facial expressions. Journal of Experimental Psychology: General. 1987; 116(3):223-237.

Silvers JA, McRae KED, Gross JJ, Remy KA, Ochsner KN. Age-Related Differences in Emotional Reactivity, Regulation, and Rejection Sensitivity in Adolescence. Emotion. 2012

Smith SM. Fast robust automated brain extraction. Human Brain Mapping. 2002; 17(3):143-155. [PubMed: 12391568]

Telzer EH, Fuligni AJ, Lieberman MD, Galván A. Ventral striatum activation to prosocial rewards predicts longitudinal declines in adolescent risk taking. Developmental Cognitive Neuroscience. 2013; 3:45-52. [PubMed: 23245219]

Telzer EH, Masten CL, Berkman ET, Lieberman MD, Fuligni AJ. Gaining while giving: an fMRI study of the rewards of family assistance among white and Latino youth. Social Neuroscience. 2010; 5(5-6):508-518. [PubMed: 20401808]

Tingley D, Yamamoto T, Hirose K, Keele L, Imai K. Mediation: R package for causal mediation analysis. R Package Version. 2013; 4(3) Retrieved from http://axis.md.tsukuba.ac.jp/web/ packages/mediation/vignettes/mediation.pdf.

Tottenham N, Tanaka JW, Leon AC, McCarry T, Nurse M, Hare TA, et al. Nelson C. The NimStim set of facial expressions: Judgments from untrained research participants. Psychiatry Research. 2009; 168(3):242-249. [PubMed: 19564050]

Trommsdorff G, Friedlmeier W, Mayer B. Sympathy, distress, and prosocial behavior of preschool children in four cultures. International Journal of Behavioral Development. 2007; 31(3):284-293.

Twisk, JWR. Applied longitudinal data analysis for epidemiology a practical guide. Cambridge, UK; New York: Cambridge University Press; 2003.

Utevsky, AV., Huettel, SA. Social Decision Making. In: Toga, AW., editor. Brain Mapping: An Encyclopedic Reference. 1st. Vol. 3. Waltham, MA: Academic Press; 2015. p. 231-234.

Van der Gaag C, Minderaa RB, Keysers C. Facial expressions: What the mirror neuron system can and cannot tell us. Social Neuroscience. 2007; 2(3-4):179-222. [PubMed: 18633816]

Van der Graaff J, Branje S, De Wied M, Hawk S, Van Lier P, Meeus W. Perspective taking and empathic concern in adolescence: gender differences in developmental changes. Developmental Psychology. 2014; 50(3):881. [PubMed: 24040846]

Van der Meer L, Groenewold NA, Nolen WA, Pijnenborg M, Aleman A. Inhibit yourself and understand the other: Neural basis of distinct processes underlying Theory of Mind. NeuroImage. 2011; 56(4):2364-2374. [PubMed: 21440642] 
Van Hoorn J, van Dijk E, Meuwese R, Rieffe C, Crone EA. Peer Influence on Prosocial Behavior in Adolescence. Journal of Research on Adolescence. 2014:n/a-n/a.

Van Goethem AAJ, van Hoof A, van Aken MAG, Orobio de Castro B, Raaijmakers QAW. Socialising adolescent volunteering: How important are parents and friends? Age dependent effects of parents and friends on adolescents' volunteering behaviours. Journal of Applied Developmental Psychology. 2014; 35(2):94-101.

Van Overwalle F, Baetens K. Understanding others' actions and goals by mirror and mentalizing systems: A meta-analysis. NeuroImage. 2009; 48(3):564-584. [PubMed: 19524046]

Venables, WN., Ripley, BD. Modern Applied Statistics with S (Fourth). New York: Springer; 2002. Retrieved from http://www.stats.ox.ac.uk/pub/MASS4

Vigneau M, Beaucousin V, Hervé PY, Duffau H, Crivello F, Houdé O, et al. Tzourio-Mazoyer N. Metaanalyzing left hemisphere language areas: Phonology, semantics, and sentence processing. NeuroImage. 2006; 30(4):1414-1432. [PubMed: 16413796]

Wager TD, Nichols TE. Optimization of experimental design in fMRI: a general framework using a genetic algorithm. NeuroImage. 2003; 18(2):293-309. [PubMed: 12595184]

Whitfield-Gabrieli, S. Region of interest extraction (REX) toolbox. Boston, MA: 2009. p. 497

Wilson TD, Schooler JW. Thinking too much: Introspection can reduce the quality of preferences and decisions. Journal of Personality and Social Psychology. 1991; 60(2):181-192. [PubMed: 2016668]

Yarkoni T, Poldrack RA, Nichols TE, Van Essen DC, Wager TD. Large-scale automated synthesis of human functional neuroimaging data. Nature Methods. 2011; 8(8):665-670. [PubMed: 21706013]

Zapf D, Dormann C, Frese M. Longitudinal studies in organizational stress research: A review of the literature with reference to methodological issues. Journal of Occupational Health Psychology. 1996; 1(2):145-169. [PubMed: 9547043] 


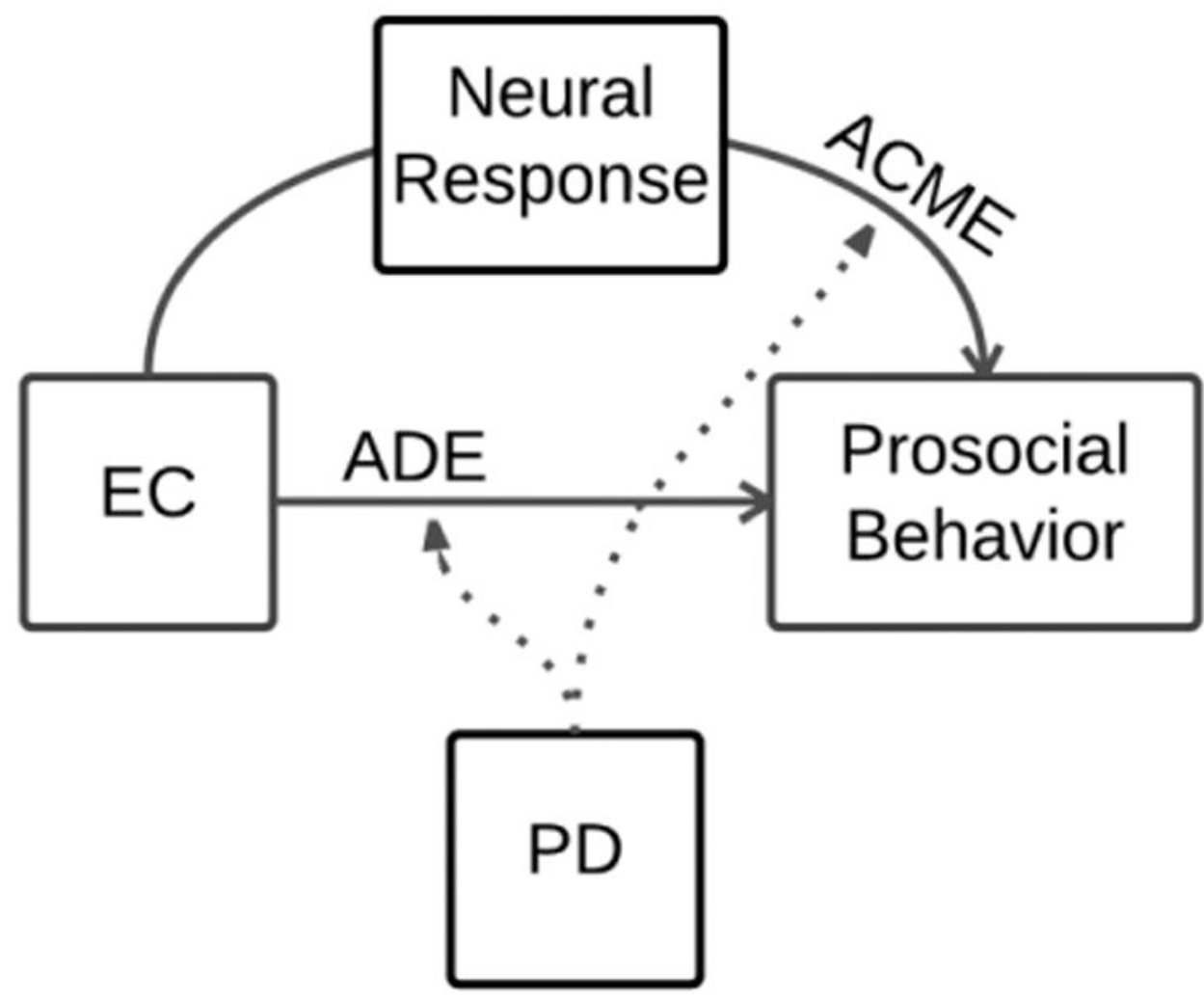

Figure 1.

Diagram of theoretical model.

Note: Solid lines indicate theoretically positive relations, and broken lines indicate theoretically negative, moderating relations. EC: empathic concern; PD: personal distress; ADE: average direct effect; ACME: average causal mediation effect. Neural response refers to brain activity during passive viewing of emotional expressions. 


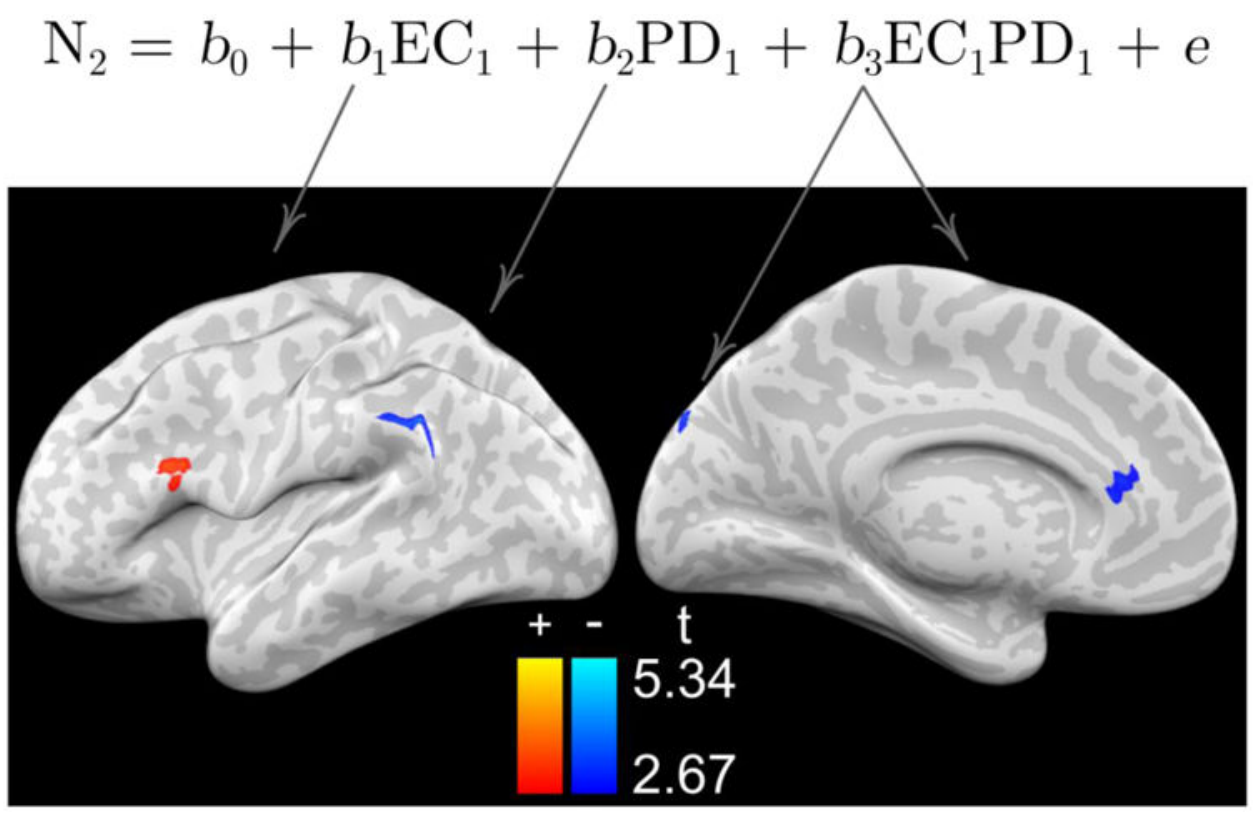

Figure 2. Neural response to emotional expressions at wave 2 associated with wave 1 empathic concern and personal distress

Note: Subscripts denote study wave (1 or 2). EC: empathic concern; PD: personal distress; $\mathrm{N} 2$ is the estimate of neural response to emotional faces. Arrows from the regression equation indicate clusters where the relevant parameter estimate exceeds the statistical significance threshold. N2was positively associated with EC1 in the left inferior frontal gyrus (IFG; warm colors, left-lateral view; $\mathrm{p}<.005, \mathrm{k}>41$ ), negatively associated with PD1 in the left inferior parietal lobule (IPL; cool colors, left-lateral view), and negatively associated with EC1PD1 in the cuneus (midline view; $\mathrm{p}<.005, \mathrm{k}>74$ ), and in the perigenual anterior cingulate cortex (ACC, on figure right; midline view; $\mathrm{p}<.005, \mathrm{k}>74$ ). 
Table 1

Descriptive Statistics for Empathic Concern, Personal Distress, and Prosocial Behavior

\begin{tabular}{|c|c|c|c|c|}
\hline IRI Subscale & Mean & SD & $a$ & $r_{12}\left(\rho_{12}\right)$ \\
\hline $\mathrm{EC}_{1}$ & 59.0 & 13.3 & 0.45 & \\
\hline $\mathrm{PD}_{1}$ & 45.1 & 13.1 & 0.45 & \\
\hline $\mathrm{EC}_{2}$ & 63.8 & 12.9 & 0.73 & $.38(.28)$ \\
\hline $\mathrm{PD}_{2}$ & 39.7 & 14.8 & 0.74 & $.19(.31)$ \\
\hline
\end{tabular}

Note: Subscripts denote study wave (1 or 2). EC: empathic concern; PD: personal distress. a is Cronbach's alpha. $r 12$ is the Pearson correlation, and $\rho_{12}$ is the Spearman rank order correlation between the variable at wave 1 and wave 2 (significant values italicized). 
Table 2

Association Between Empathic Concern at Wave 1 and Prosocial Behavior at Wave 2

\begin{tabular}{|c|c|c|c|c|}
\hline Parameter & $B$ & $\mathrm{SE}(B)$ & $t(51)$ & $p$ \\
\hline Intercept & 43.94 & 7.68 & 5.72 & $<.01$ \\
\hline $\mathrm{PSB}_{1}$ & 0.08 & 0.15 & 0.55 & .58 \\
\hline $\mathrm{EC}_{1}$ & 0.44 & 0.18 & 2.42 & .02 \\
\hline $\mathrm{PD}_{1}$ & -0.16 & 0.18 & 0.89 & .38 \\
\hline $\mathrm{EC}_{1} \times \mathrm{PD}_{1}$ & 0.00 & 0.01 & -0.14 & .89 \\
\hline
\end{tabular}

Note: Subscripts denote study wave (1). EC: empathic concern; PD: personal distress; PSB: prosocial behavior. 

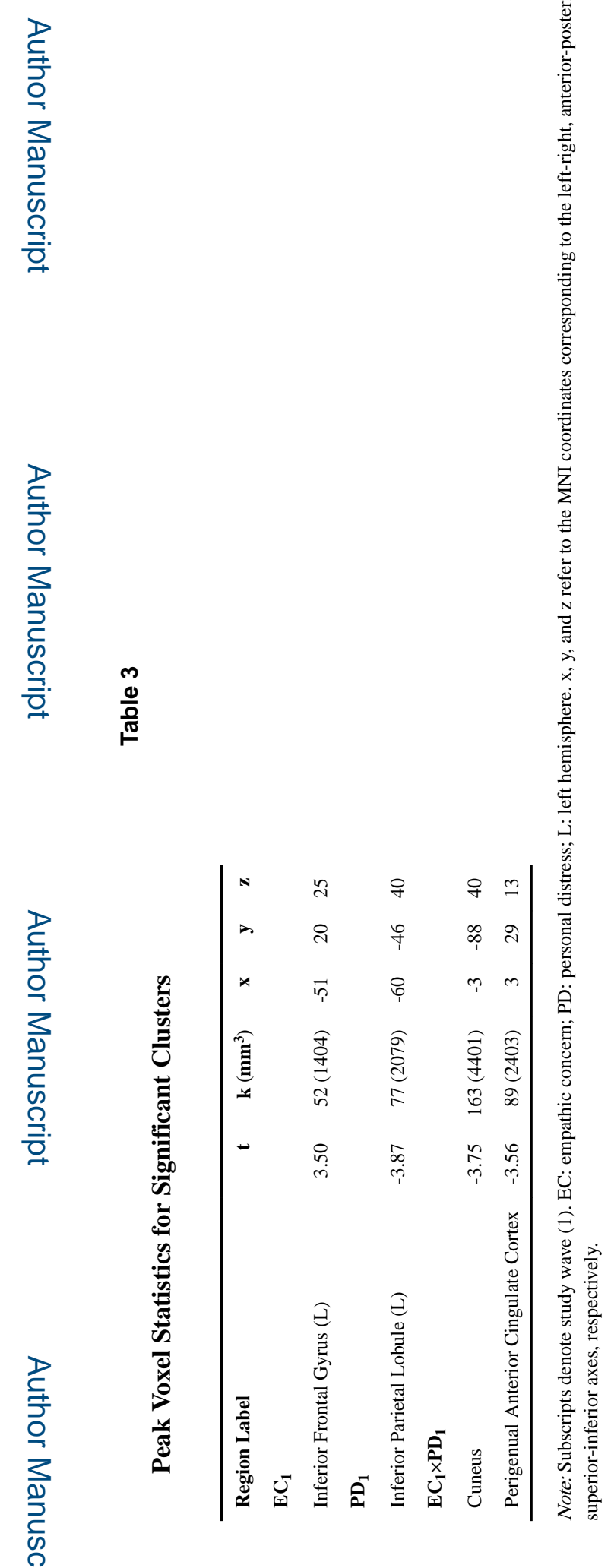
Table 4

Estimates of Mediated, Direct and Total Effects of Empathic Concern on Prosocial Behavior

\begin{tabular}{lrrrr} 
& Estimate & 95\% CI Lower & 95\% CI Upper & $\boldsymbol{p}$ \\
ACME & 3.608 & 0.930 & 7.267 & 0.00 \\
ADE & 3.304 & -2.057 & 8.389 & 0.22 \\
Total Effect & 6.912 & 1.790 & 11.966 & 0.01 \\
Prop. Mediated & 0.511 & 0.128 & 1.709 & 0.01 \\
\hline
\end{tabular}

Note: Estimates of the average direct effect (ADE), average causal mediated effect (ACME), and total effect on the prosocial behavior outcome for a $1 \mathrm{SD}$ change in empathic concern. Prop. Mediated is an estimate of the ratio between the ACME and total effect. 